\title{
A Three-Phase Grid-Connected Inverter for Photovoltaic Applications Using Fuzzy MPPT
}

\author{
Jaime Alonso-Martínez, Santiago Arnaltes \\ Dpt. of Electrical Engineering, Univ. Carlos III de Madrid \\ Avda. Universidad 30, 28911 Leganés (Madrid) \\ Tel:+34 916249949 - Fax:+34 916249430 - jalonsom@ing.uc3m.es
}

\begin{abstract}
This paper presents a three-phase grid-connected inverter designed for a $100 \mathrm{~kW}$ photovoltaic power plant that features a maximum power point tracking (MPPT) scheme based on fuzzy logic. The whole system presented is simulated in Matlab. This fuzzy MPPT shows accurate and fast response, and is integrated in the inverter, so that a DC-DC converter is not needed. The inverter allows full control of reactive power.
\end{abstract}

Keywords - Photovoltaic, Inverter, MPPT, Fuzzy logic, Power electronics.

\section{Introduction}

Photovoltaic systems are increasing in size as they become more affordable and supporting schemes start to include larger installations. In a near future, photovoltaic systems of $100 \mathrm{~kW}$ peak power or more are going to be very common, and it is expected that they will contribute with a significant share to power generation.

In such a scenario, the contribution to the grid stability of PV systems is likely to become relevant[2], as it has already happened with other renewable energies like wind power in some countries. In Spain, for instance, wind farm operators are encouraged to contribute to system stability by means of a remuneration for reactive power control. The requirements for robust operation under grid faults and perturbances have also increased. This could be applied to PV systems once they reach a certain amount of installed power in a given region.

Proper integration of medium or large PV systems in the grid may therefore require additional functionality from the inverter, such as reactive power control. Furthermore, the increase of average PV system size may lead to new strategies like eliminating the DC-DC converter that is usually placed between the PV array and the inverter, and moving the MPPT to the inverter, resulting in increased simplicity, overall efficiency and a cost reduction. These two characteristics are present in the three-phase inverter that is presented here, with the addition of a fuzzy MPPT control that shows excellent performance.

\section{Proposed System Description}

The system that has been simulated consists of a photo- voltaic array with a peak power of $100 \mathrm{~kW}$ connected through a DC bus to a three-phase inverter that is connected to an ideal $400 \mathrm{~V}$ grid through a simple filter, as shown in Fig. 2.

The MPP tracker is integrated in the inverter control (Fig. 3 ), as there is no DC-DC converter in the chosen configuration.

The whole system was simulated in Matlab-Simulink.

\section{A. PV Array Simulation}

The PV array is simulated using a model of moderated complexity based on [1]. In this model, a PV cell is represented by a current source in parallel with a diode, and a series resistance as shown in Fig. 1. There is no need for a more complex model with a second diode and / or a shunt resistance. The photo current $I_{p h}$ depends on the irradiance $G$ and the cell temperature $T^{c}$. The current $I^{c}$ provided by the cell can be calculated as:

$$
I^{c}=I_{p h}-I_{D}=I_{p h}-I_{0}\left(\exp \frac{e\left(V+I R_{s}\right)}{n k T^{c}}-1\right)
$$

Where the saturation current $I_{0}$ is temperature dependent, $e$ is the charge of an electron, $k$ is Boltzmann's gas constant and $n$ is the idealising factor of the diode.

The module is an association of solar cells in parallel and series. Extending the previous cell model to a module, a similar equation can be found. But it is more useful to express such an equation in terms of the open circuit voltage $V_{o c}$ and short circuit current $I_{s c}$, as these can be es-

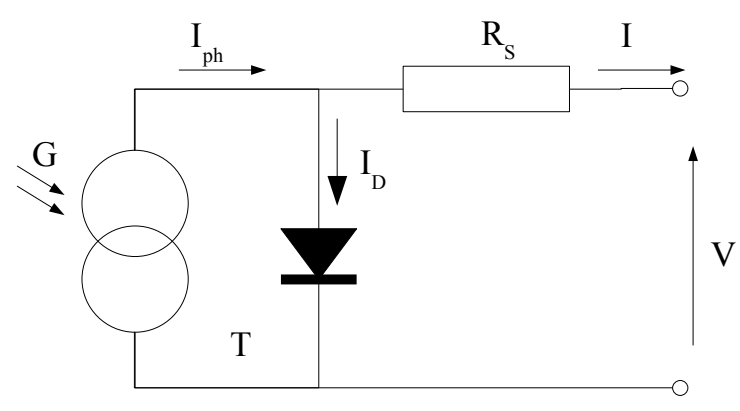

Fig. 1: Equivalent circuit of a PV cell 


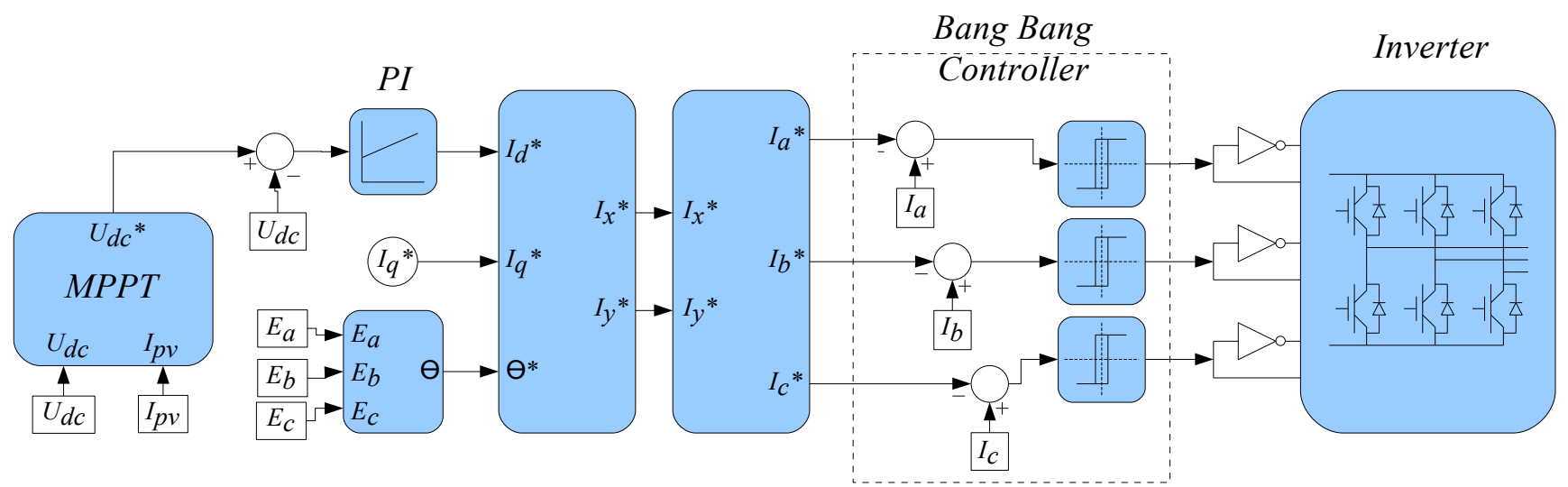

Fig. 2: Proposed control scheme

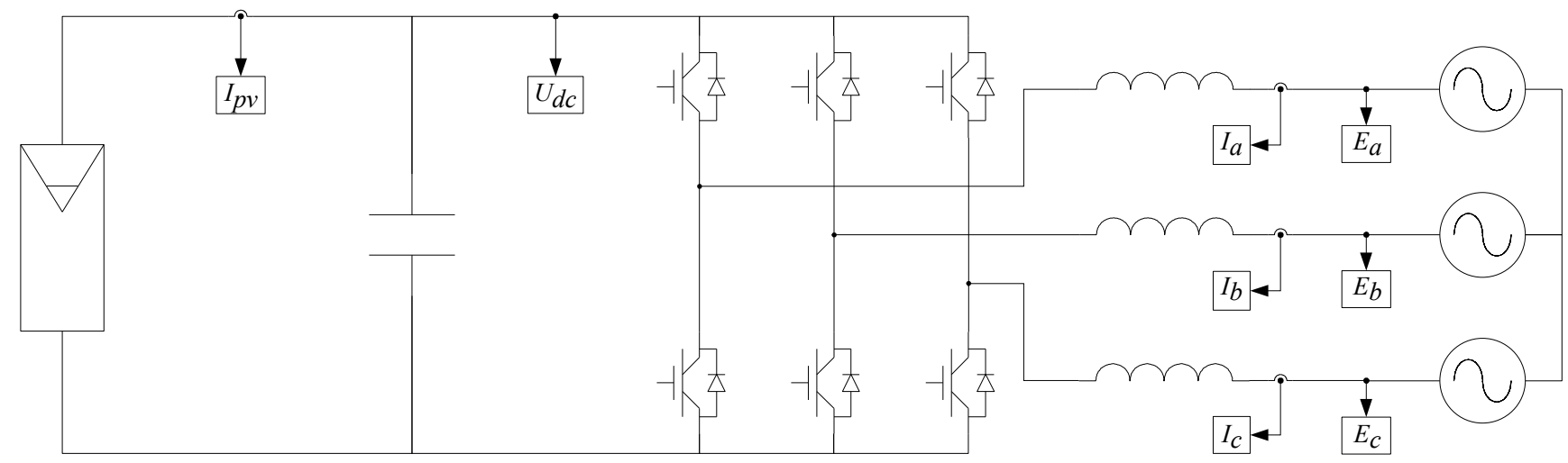

Fig. 3: Proposed electrical scheme

timated from the open circuit voltage and short circuit current in standard conditions that are usually provided by module manufacturers, and their linear dependence on $T^{c}$ and $G$ respectively.

The cell temperature $T^{c}$ is estimated considering its linear dependence on $G$ and the cell temperature in normal operating conditions that is provided by the module manufacturer.

The final model used to determine the relationship of a module current and voltage is shown in equation (2), where $m$ designs module magnitudes.

$$
I^{m}=I_{s c}^{m}\left(1-\exp \frac{e\left(V^{m}-V_{o c}^{m}+I^{m} R_{s}^{m}\right)}{N_{s} \cdot n k T^{c}}\right)
$$

The model parameters were adjusted to simulate the stat-

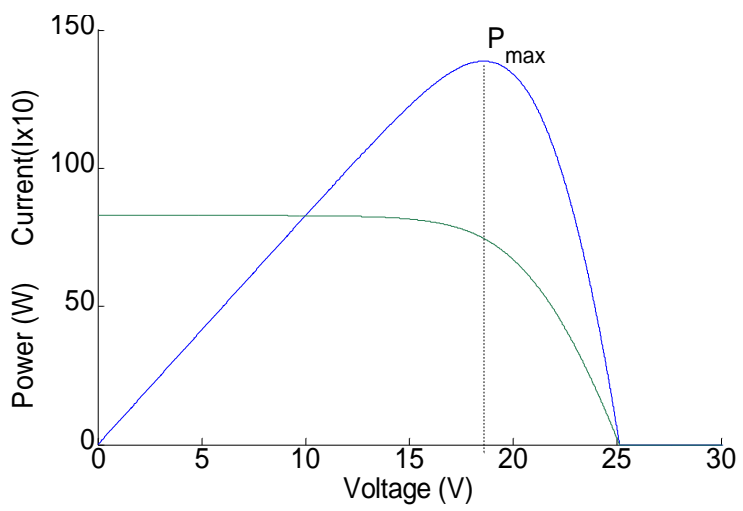

Fig. 4: Module power and current vs. voltage for $\mathrm{G}=1000 \mathrm{~W} / \mathrm{m} 2$ and $\mathrm{T}=298 \mathrm{~K}$ ic response of a Kyocera KC167GH-2 module based on the data provided by the manufacturer.

The PV array is made of 20 strings of 35 series connected modules each, connected in parallel. This gives a total peak power of around $100 \mathrm{~kW}$. All modules are considered to be identical, and to work in identical conditions of temperature and irradiance.

\section{B. Fuzzy MPPT}

For a given set of operating conditions $G$ and $T$ our module model shows that the relationship between voltage, current and power are functions similar to the ones shown in Fig. 4. The voltage that corresponds to the module maximum power varies with temperature and irradiance variations, so a MPP tracking system is needed to ensure that we stay as close as possible to the optimum. Usual MPPT methods include Perturb and Observe (P\&O) [3], incremental conductance [4], fuzzy logic [5] and other $[6,7]$ methods.

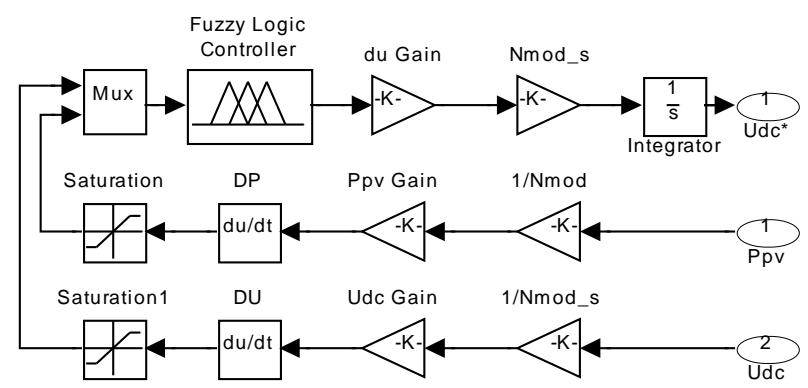

Fig. 5: Fuzzy MPPT diagram 


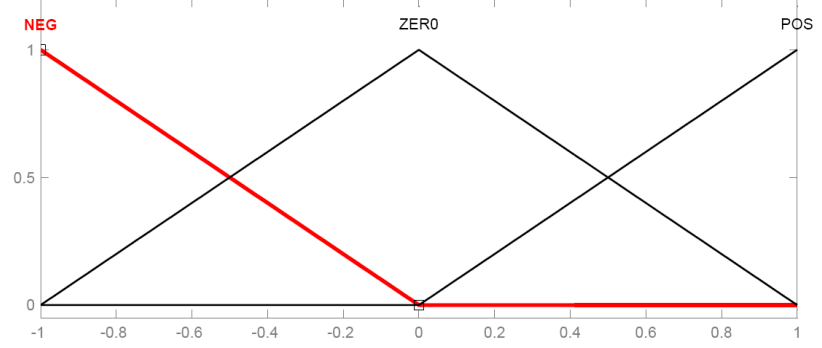

Fig. 6: Membership function plots for $\Delta U_{d c} \Delta P_{p v}$ and $\Delta U_{d c}{ }^{*}$

Here a method based on a fuzzy controller is presented that differs from current ones, as it has been designed to be integrated in the inverter instead of a DC-DC converter, and uses a reduced set of membership functions (and therefore is simpler to fine-tune) without compromising performance.

Fuzzy logic controllers are suitable for nonlinear problems where the desired system behaviour in terms of input and output variables can be expressed as a set of semantic rules. They present a robust performance and good response in noisy environments.

Usually the MPPT controls a DC-DC converter to maintain a constant $\mathrm{DC}$ voltage at the output of the generator. With an appropriate sizing of the PV array the DC-DC converter can be avoided due to the relatively small changes in the optimum voltage in operating conditions. This will save one stage in the system and therefore will increase efficiency.

In the usual configuration with a DC-DC converter the MPPT system outputs a signal to change the duty cycle of the converter. In this case, the MPPT will output a DC voltage reference $U_{d c} *$ to the inverter control.

As inputs, the MPPT will need the DC bus voltage $U_{d c}$ and the power delivered by the PV array $P_{p v}$, which is obtained as the product of $U_{d c}$ and the PV array current. The increment of these variables $\Delta U_{d c}$ and $\Delta P_{p v}$ over a sample period are computed, which are going to be the inputs of the fuzzy logic controller. The output will be $\Delta U_{d c}$ * which is then integrated to obtain the desired reference $U_{d c}{ }^{*}$.

A gain is applied to all variables in order to fine tune the controller response. These gains are separated in Fig. 5 in two groups: a first group that brings variable levels to a module level (so that the MPPT can be tuned for a single module, and remain tuned for different PV array configurations) and a second group that controls the MPPT dynamic response.

These inputs and output were chosen as it is easy to ex-

Table 1: Fuzzy rules

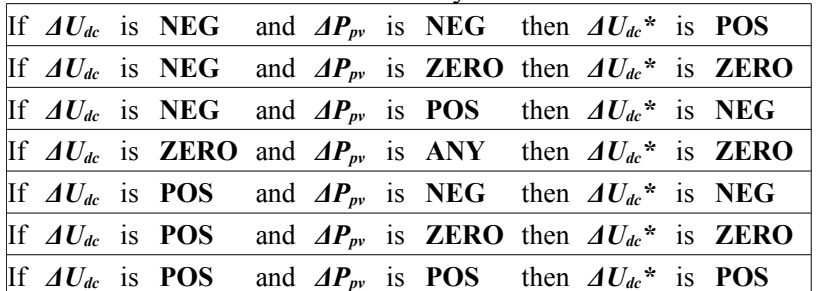

press a set of semantic rules that lead to maximum power point tracking. The shape of the P-V curve (Fig. 4) makes suitable a hill-climbing approach to search the maximum. The chosen rules are shown in Table 1.

Usually, a large number of membership functions are defined, such as negative-big, negative-medium, negative-small, etc. This is not necessary, and it introduces an additional complexity to the controller tuning, as the boundaries between seven or more membership functions have to be defined, for each variable. In this case we have chosen a set of three membership functions: negative (NEG) positive (POS) and zero (ZERO). Their shapes for all input and output variables are the same as shown in Fig. 6. They are all normalised to [-1 1$]$ and [ $\left[\begin{array}{ll}0 & 1\end{array}\right]$ so the characteristics are controlled by the input and output gains. This reduces tuning complexity.

\section{Inverter}

The inverter control is based on a decoupled control of the active and reactive power.

The DC voltage is set by a PI controller that compares the actual DC bus voltage and the reference generated by the MPPT, and provides a $I_{d} *$ active current reference in a synchronous reference frame attached at grid voltage vector. The other component of current vector represents the reactive current and it can be fixed at the desired level for power factor or voltage control. By applying the inverse Park transformation to d-q current vector components, the desired $I_{a b c} *$ phase current references are obtained. These are passed to a bang bang controller, which outputs the pulses to drive the inverter switches. The output line voltage of the inverter is shown in Fig. 7.

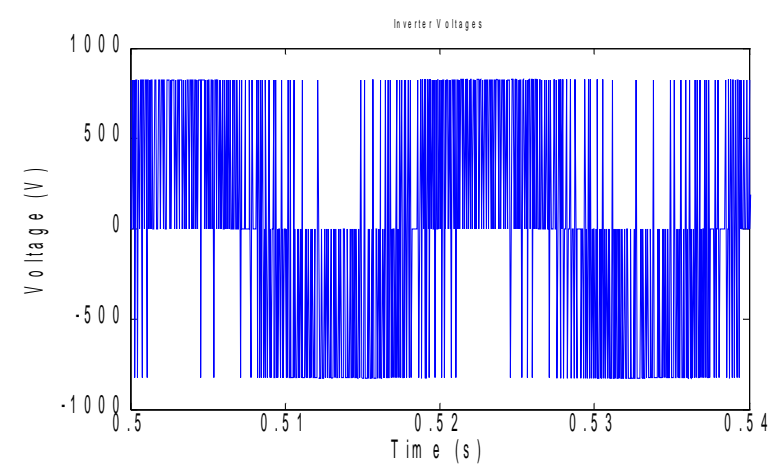

Fig. 7: Inverter Line Voltage. Only one phase is shown.

As there is no DC/DC converter between the PV generator and the inverter, the PV array configuration has to be chosen so that the output voltage of the PV generator suits the inverter's requirements.

In this case a $400 \mathrm{~V}$ grid has been chosen, so the inverter will need at least $600 \mathrm{~V}$ in the DC bus in order to be able to operate properly.

The lowest DC voltage will occur with high ambient temperature and high irradiance (because the irradiance increases the cell temperature, and this effect predominates over the increase of optimal voltage caused by an increment of the irradiance at a constant cell temperature), so 
the minimum number of series connected modules should be determined by this worst case. As the PV array model estimates cell temperature as a function of irradiance and ambient temperature, for the worst case an ambient temperature of $50^{\circ} \mathrm{C}$ and an irradiance of $G=1000 \mathrm{~W} / \mathrm{m}^{2}$ were chosen. The PV array was found to require 35 series connected modules per string.

The optimal voltage for this configuration should stay around $700-800 \mathrm{~V}$ most of the time, with some peaks that could reach a minimum of $600 \mathrm{~V}$ and a maximum of $900 \mathrm{~V}$ in very extreme situations. The only drawback of such a voltage is a slight increase of the inverter price as higher rated voltage of DC link capacitors and switches are required.

\section{Simulation Results}

In Fig. 8 and Fig. 9 the system response to an irradiance step is shown. In $t=0.2 \mathrm{~s}$ the irradiance is changed from 150 to $1000 \mathrm{~W} / \mathrm{m}^{2}$. It can be seen that the system tracks the new operating point very quickly, faster than most MPPT strategies. It has to be said that this is an extreme change in irradiation levels that is unlikely to occur but shows the good performance of the MPPT.

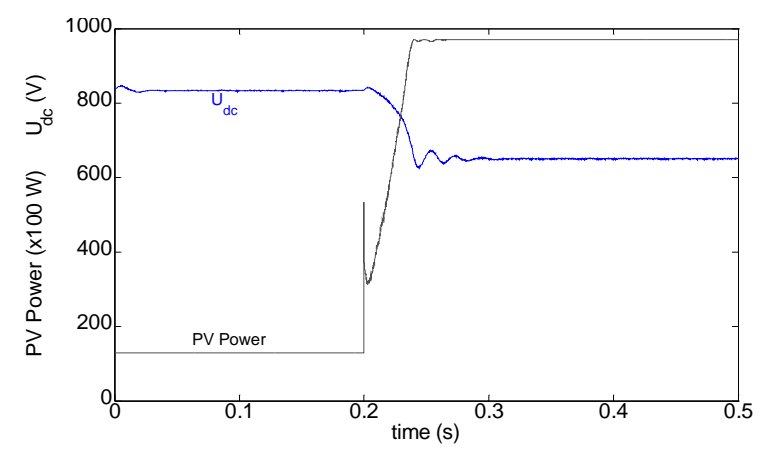

Fig. 8: System response to an irradiance step in $\mathrm{t}=0.2 \mathrm{~s}$

The maximum power point is tracked with excellent accuracy as can be seen in Fig. 9, where the generated power is compared to the theoretical optimum calculated from the PV array model.

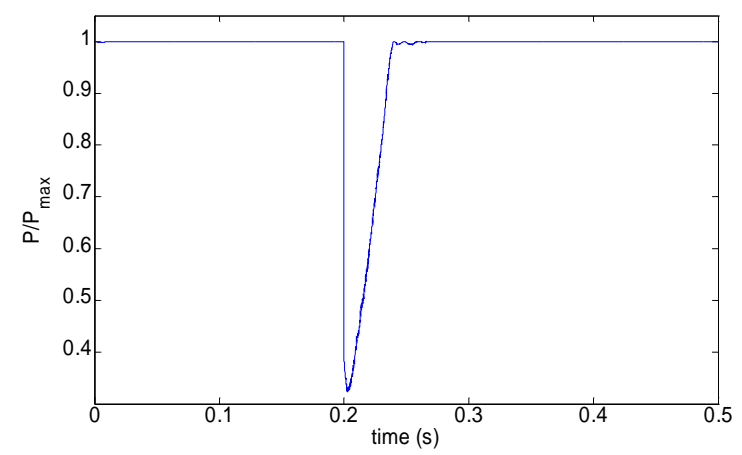

Fig. 9: System response to an irradiance step in $\mathrm{t}=0.2 \mathrm{~s}$

In Fig. 10 is shown the system response to a step in the reactive current reference. Only one phase is shown in order to clearly see the reference step. Before $\mathrm{t}=0,35 \mathrm{~s}$ voltage and current are in phase, until the step command is applied and current leads voltage afterwards. A great advantage of this inverter control scheme is the ability to control power factor instantaneously, and with good accuracy.

In Fig. 11 are represented the grid currents and voltages at unity power factor, showing good performance.

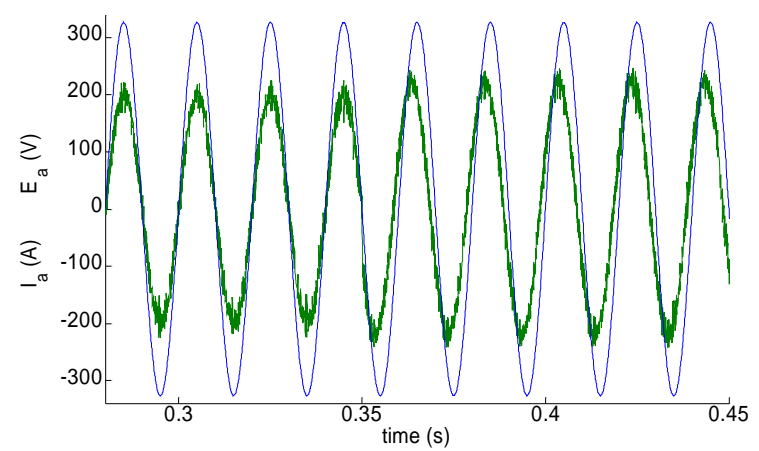

Fig. 10: Inverter response to a step in reactive power reference in $\mathrm{t}=0.35 \mathrm{~s}$. For clarity, only one phase is shown.

\section{Conclusion}

An inverter for medium or large photovoltaic applications has been presented. The inverter features decoupled control of active and reactive power. It does not require an intermediate stage of DC/DC control, as the optimum $\mathrm{DC}$ voltage is set by the inverter itself by means of a fuzzy MPPT.

The simulation of the whole system has been done in Matlab-Simulink and it shows an excellent performance of both inverter and MPPT, with negligible fluctuation of the DC bus voltage, fast tracking of optimum operating point, and almost instantaneous tracking of power factor reference.

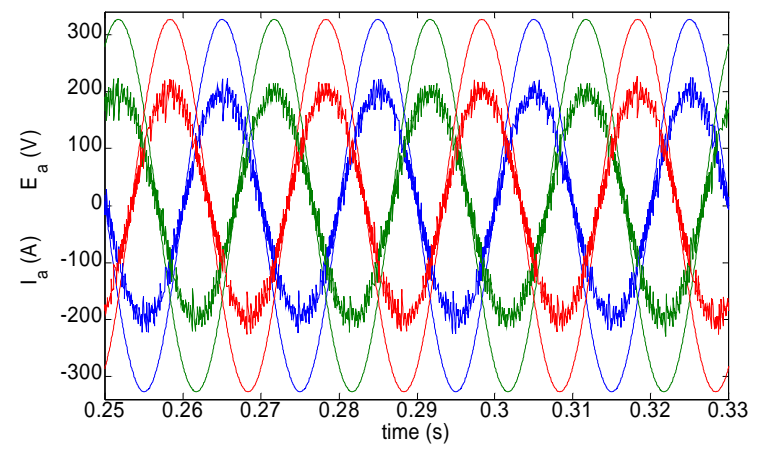

Fig. 11: Inverter behaviour in operation at unity power factor

\section{References}

[1] Anca D. Hansen, Poul Sørensen, Lars H. Hansen and Henrik Bindner, "Models for a Stand-Alone PV System", Risø-R-1219(EN) / SEC-R-12, 2000

[2] Yun Tiam Tan, Daniel S. Kirschen, Nicholas Jenkins, "A Model of PV Generation Suitable for Stability Analysis" in IEEE Transactions on Energy Conversion, vol. 19, no. 4, December 2004

[3] H. Yongji and L. Deheng, "A new method for optimal output of a solar cell array," in Proc. IEEE Int. Symp. Industrial Electronics, 1992, vol.1, pp. 456-459.

[4] C. R. Sullivan and M. J. Powers, "A high-efficiency maximum power point tracker for photovoltaic array in a solarpowered race vehicle," in Proc. IEEE PESC, 1993, pp. 
$574-580$

[5] N. Patcharaprakiti and S. Premrudeepreechacharn, "Maximum power point tracking using adaptive fuzzy logic control for grid-connected photovoltaic system", in IEEE Power Engineering Winter Meeting, 2002

[6] D. Shmilovitz, "On the control of photovoltaic maximum power point tracker via output parameters"IEE Proc.-Electr. Power Appl., Vol. 152, No. 2, March 2005

[7] G. Walker, "Evaluating MPPT converter topologies using a MATLAB PV model," J. Elect. Electron. Eng., vol. 21, no. 1, pp. 49-56, 2001.
[8] Hudson, R.M.; Behnke, M.R.; West, R.; Gonzalez, S.; Ginn, J. "Design considerations for three-phase grid connected photovoltaic inverters" in Photovoltaic Specialists Conference, 2002. Conference Record of the TwentyNinth IEEE 19-24 May 2002 Page(s):1396 - 1401

[9] Liserre, M.; Teodorescu, R.; Blaabjerg, F. "Stability of Photovoltaic and Wind Turbine Grid-Connected Inverters for a Large Set of Grid Impedance Values" in Power Electronics, IEEE Transactions on Volume 21, Issue 1, Jan. 2006 Page(s):263 - 272 